\title{
Aspectos da toxoplasmose na clínica de pequenos animais
}

\section{Clinical aspects of toxoplasmosis in small animal}

\author{
André Luiz Baptista Galvão ${ }^{1 *}$; Amanda Leal de Vaconcellos ${ }^{1}$; \\ Italmar Teodorico Navarro ${ }^{2}$; Katia Denise Saraiva Bresciani ${ }^{3}$
}

\section{Resumo}

\begin{abstract}
A toxoplasmose, zoonose de distribuição mundial, apresenta importância em medicina veterinária e saúde pública. Os animais podem ser a fonte direta ou indireta da infecção ao homem, e neste, esta doença pode ser responsável por encefalite e óbitos, devido sua forma congênita em neonatos e como coinfecção em pacientes portadores da síndrome da imunodeficiência adquirida. O homem e os animais, hospedeiros intermediários, podem adquirir a doença pelo consumo de alimentos, como carne crua ou mal cozida e água contaminados com cistos e oocistos de $T$. gondii, respectivamente. Via iatrogênica como transfusões de sangue e transplante de órgãos são outras formas menos frequentes de transmissão. $\mathrm{O}$ agente causador desta enfermidade é o Toxoplasma gondii, protozoário coccídio intracelular obrigatório. Em pequenos animais, esta infecção tem sido reportada em diversos países, promovendo manifestações clínicas variadas e incomuns, porém severas e fatais, que constituem em um desafio em diagnóstico na clínica de pequenos animais, principalmente quando no comprometimento do sistema nervoso. Desse modo, constituem no objetivo da presente revisão literária abordar a participação dos pequenos animais na disseminação da doença, os aspectos clínicos a ela relacionados, bem como discutir métodos de diagnóstico, medidas terapêuticas, de profilaxia e controle desta enfermidade.
\end{abstract}

Palavras-chave: Cão, gato, imunossupressão, protozoário, zoonose

\begin{abstract}
Toxoplasmosis, a zoonosis of worldwide distribution, has importance in human and veterinary medicine. Animals can be direct or indirect source of infection to man, and this intermediate host, the disease may be responsible for encephalitis and deaths due to congenital form as coinfection in neonates and patients with acquired immunodeficiency syndrome. The man and animals can acquire the disease by eating undercooked meat or cures, infected with tissue cysts, as well as food and water contaminated with oocysts. Iatrogenic, such as, blood transfusion and organ transplantation are other less frequent routes of transmission. The causative agent of this disease is Toxoplasma gondii, a protozoan obligate intracellular coccidian. In small animals, the infection has been reported in several countries, promoting varied clinical manifestations and uncommon but severe and fatal, which is a challenge in the clinical diagnosis of small animals, especially when the nervous system involvement. Thus, constitute the purpose of this review address the participation of small animals in the spread of the disease, clinical aspects related to it, as well as discuss methods of diagnosis, therapeutic measures, prophylaxis and control of this disease.
\end{abstract}

Key words: Dog, cat, immunosuppresion, protozoan, zoonosis

\footnotetext{
${ }^{1}$ Discentes de Doutorado em Medicina Veterinária, Faculdade de Ciências Agrárias e Veterinárias, UNESP, Universidade Estadual Paulista Julio de Mesquita Filho, Campus de Jaboticabal, SP. E-mail: andrelgalvao@hotmail.com; amanda-vet@hotmail.com

2 Prof. Dr. do Centro de Ciências Agrárias, Universidade Estadual de Londrina, UEL, Londrina, PR. E-mail: italmar@uel.com.br

${ }^{3}$ Prof ${ }^{a}$ Adjunto da UNESP, Faculdade de Medicina Veterinária de Araçatuba, Araçatuba, SP. E-mail: bresciani@fmva.unesp.br

* Autor para correspondência
} 


\section{Introdução}

A toxoplasmose possui como agente etiológico o Toxoplasma gondii, protozoário coccídio intracelular obrigatório, parasito pertencente ao Reino Protista, Sub-reino Protozoa, Filo Apicomplexa Gênero Toxoplasma e Espécie T.gondii (NICOLLE; MANCEAUX, 1909; FRENKEL; DUBEY, 1972).

A infecção por T.gondii apresenta importância na medicina humana e veterinária, por ocasionar aborto e alterações congênitas em várias espécies de hospedeiros intermediários, incluindo o homem (TENTER; HECKEROTH; WEISS, 2000).

Em seres humanos, conforme inquéritos soroepidemiológicos para $T$. gondii, foram constatados que a titulação de anticorpos aumenta com a idade em ambos os sexos e varia de acordo com os fatores climáticos, hábitos alimentares e/ou higiênicos (SÁFADI, 2000).

Bichara (2001) estudou o perfil sorológico de toxoplasmose na área metropolitana de Belém, selecionando os índividuos de acordo com a apresentação clínica. A prevalência total da doença de $78 \%$ e a distribuição percentual encontrada foi, de $69 \%, 72 \%, 78 \%$ e $90 \%$ nos grupos com infecção congênita, com linfadenopatia e febre, em portadores da síndrome da imunodeficiência adquirida (SIDA) e com a forma ocular, respectivamente.

A encefalite toxoplásmica esta diretamente correlacionada com a positividade para o parasito supramencionado na população de indivíduos portadores da SIDA. Nestes, o risco estimado de reativação da enfermidade com o comprometimento de sistema nervoso central varia de $12 \%$ a $47 \%$ (BORGES; FIGUEIREDO, 2004).

Em humanos, a toxoplasmose se desenvolve não somente em situações de imucomprometimento devido ao vírus da imunodeficiência humana, outras patologias/condições podem estar associadas, tais como: linfomas, leucemias, transplantes de órgãos ou uso prolongado de citostáticos e corticosteróides (FRENKEL; BERMUDEZ, 2006).
Neonatos com toxoplasmose congênita podem apresentar manifestações neurológicas (hidrocefalia, microcefalia e retardo mental), lesões oftálmicas, comprometimento auditivo e até ocorrência de morte de neonatos após o nascimento devido a toxoplasmose (GROËR et al., 2011; PORTO; DUARTE, 2012; FAUCHER et al., 2012; FERNANDES et al., 2012; LOPES-MORI et al., 2013), por isso tem sido implantados projetos bem sucedidos de controle da referida enfermidade (NAVARRO et al., 2013).

Em animais de companhia, as manifestações clínicas da toxoplasmose são muito variadas e similares a outras enfermidades, com envolvimento de vários órgãos e sistemas como o gastrintestinal, linfático, hematopoiético, hepático, respiratório, muscular-esquelético, cardiovascular, ocular e nervoso.

Abordar a participação dos pequenos animais na propagação da doença, os aspectos clínicos, discutir métodos em diagnóstico e medidas terapêuticas, bem como ações profiláticas e de controle sobre esta enfermidade consiste no objetivo da presente revisão.

\section{Aspectos Epidemiológicos}

\section{Formas evolutivas}

$\mathrm{Na}$ toxoplasmose, basicamente existem três formas evolutivas: oocistos nas fezes de hospedeiros definitivos, liberados em determinados períodos; taquizoítos, presentes nos fluidos orgânicos durante a fase aguda da doença e os bradizoítos, contidos no interior dos cistos, no sistema nervoso e nos músculos na fase crônica da enfermidade (LAPPIN, 2005; GADEMARTORI, 2007).

Aingestãode cistosteciduais em produtos cárneos, o consumo de alimentos e água contaminados com oocistos esporulados e a infecção congênita por taquizoítos representam as três formas principais de transmissão de T. gondii (DUBEY, 1986). Outras vias, com menor importância epidemiológica, 
incluem ingestão de leite contaminado, transferência de fluídos orgânicos, transplante de órgãos (DUBEY; GREENE; LAPPIN, 1990; POWELL; BREWER; LAPPIN, 2001; MIRÓ et al., 2004).

Cães podem atuar como veiculadores de oocistos de T.gondii se ingerirem material fecal contaminado ou rolarem em fezes de gatos, carreando eventualmente oocistos em sua pelagem (FRENKEL; PARKER, 1996; LINDSAY et al., 1997, ETHEREDGE et al., 2004, SCHARES et al., 2005).

Gatos também podem ser hospedeiros intermediários e abrigar estágios extra-intestinais, no ciclo assexuado (MILLER; FRENKEL, DUBEY, 1972, DUBEY; MATTIX; LIPSCOMB, 1996; URQUHART et al., 1998, DUBEY et al., 2002, FRENKEL; BERMUDEZ, 2006), assim como outros mamíferos (incluindo o homem), aves, répteis, anfíbios e peixes (GADEMARTORI, 2007).

Pássaros e outros animais de estimação, tampouco pombos, não transmitem a infecção, uma vez que são hospedeiros intermediários e assim não eliminam oocistos pelas fezes. Para que houvesse a transmissão por meio destes hospedeiros, seria necessária a ingestão da carne ou vísceras desses animais (MONTEIRO, 2010).

Em relação aos aspectos biológicos, felídeos são os únicos hospedeiros definitivos, com ciclo enteroepitelial, onde ocorre esquizogonia, merogonia, gametogonia e formação de oocistos (FRENKEL; DUBEY.; MILLER, 1970). Estes últimos, formas evolutivas são eliminadas nas fezes de felinos domésticos e silvestres, por esporogonia, tornam-se infectantes, sendo muito resistentes ás condições ambientais (MILLER; FRENKEL, DUBEY, 1972). elucidação do ciclo evolutivo do T. gondii, foi possível por meio dos estudos de Hutchison, Dunachie e Work (1968), Hutchison et al. (1970, 1971), Witte e Piekarski (1970) e Frenkel (1973).

Importante mencionar que felídeos infectados jovens, podem eliminar oocistos nas fezes aproximadamente por uma a duas semanas. Estes, em condições ambientais favoráveis, podem se manter infectantes por aproximadamente de 12 a 24 meses. Adultos imunocompetentes geralmente não excretam estas formas evolutivas, mas quando imunosuprimidos podem eliminar alguns oocistos, porém em quantidades inferiores às encontradas na infecção primária (DUBEY, 1995).

Os gatos defecam e enterram suas fezes em terra fofa ou areia, estas são consistentes e podem permanecer no local por meses. A menos que o gato esteja doente, pouco ou nenhum resíduo fecal fica aderido à região perianal e em geral, não apresentam diarréia durante o período de excreção dos oocistos. Por causa de seus cuidadosos hábitos de limpeza, matéria fecal não é encontrada na pelagem de animais clinicamente normais (portanto a possibilidade de transmissão para seres humanos pelo ato de tocar ou acariciar um gato é mínima ou inexistente) (BRESCIANI et al., 2013).

Importante atentar para estes peculiaridades do comportamento do felino e também enfatizar, que os oocistos são eliminados por estes hospedeiros definitivos, mas necessitam permanecer no ambiente, pelo menos um dia, sob determinadas condições de temperatura e umidade e esporular para se tornarem infectantes.

\section{Estudos em Pequenos Animais}

Freire et al. (1992), no período de 1985 a 1990, realizaram 254 exames de imunofluorescência indireta em cães com sinais clínicos suspeitos de toxoplasmose atendidos no Hospital Veterinário da Universidade Estadual de Londrina, constatando que $75,98 \%$ destes animais apresentaram titulação de anticorpos para T. gondii.

No Hospital Veterinário da Universidade Estadual de Londrina, Navarro et al. (1997), verificaram que o plasma pode ser utilizado como material alternativo para pesquisa de anticorpos contra $T$. gondii, pois este demonstrou titulações 
de anticorpos nas amostras equivalentes as dos soros neste trabalho comparativo. Adicionalmente, $23,40 \%$ de cães foram reagentes para o protozoário supramencionado.

Interessante notar que após a primo-infecção experimental de oocistos e taquizoítos de $T$. gondii em cadelas, foi possível detectar este parasito em amostras de saliva, leite e urina pelo bioensaio em camundongos (BRESCIANI et al., 2001).

Por técnicas sorológicas, Cãnon-Franco et al. (2004) e Bresciani et al. (2007) caracterizaram que cães errantes e mantidos em ambientes de grama e com terra, respectivamente, são mais predisponentes à infecção por $T$. gondii.

Marques et al. (2009) avaliaram a frequência de anticorpos para $T$. gondii em propriedades rurais localizadas no município de Eldorado, Mato Grosso do Sul, Brasil, sendo constatado a frequência de animais reagentes ao teste de detecção de anticorpos de: 22,86\% (46/201) em aves, 5,15\% (20/388) em bovinos, 47,61\% (20/42) em cães, 60,87\% (14/23) em equídeos, $57,14 \%$ (8/14) em gatos, $14,7 \%$ (5/34) em suínos e negatividade em ovinos. A elevada frequência de anticorpos encontrada, alerta a possibilidade de risco para os humanos uma vez que estas espécies compartilham as mesmas fontes de infecção com o homem ou servem de alimento para ele na região estudada.

Silva-Filho et al. (2012) estudaram a infecção por T. gondii e Leishmania spp. em humanos e cães de assentamentos rurais no norte do estado do Paraná, Brasil. Pela imunofluorescência indireta foram estudadas as amostras de sangue coletadas de 216 pessoas e 169 cães. A prevalência de toxoplasmose em humanos foi de 79,1\% e em cães foi de $82,2 \%$, para leishmaniose foi observada a prevalência de $7,4 \%$ em humanos e $8,2 \%$ em cães. Os autores concluíram que existe uma grande propagação de T. gondii em ambas as espécies e a ocorrência de anticorpos anti-Leishmania ssp. em humanos e cães, indicam que ocorre transmissão de Leishmania spp. nas localidades estudadas.
Em estudo de reinfecção toxoplásmica durante a gestação, os produtos dessas mães nasceram aparentemente saudáveis mas sorologicamente positivos (BRESCIANI et al., 2009).

Moura et al. (2009) constataram que fatores como raça não definida, acesso à rua e alimentação à base de dieta caseira, foram fatores predisponentes para a infecção por T. gondii em 400 caninos, em Santa Catarina, Brasil. Os residentes no Balneário Camboriú apresentaram positividade de $22,3 \%$ e na cidade de Lages, $26 \%$.

Em investigação sorológica de 530 cães pela RIFI, foi constatado que $18 \%$ apresentaram titulação positiva para $T$. gondii. Estes haviam sido atendidos no Hospital Veterinário da Universidade Federal do Piauí, Brasil, local onde não haviam relatos da ocorrência desta enfermidade (LOPES et al., 2011).

Araújo et al. (2011) em Porto Figueira, Paraná, Brasil, encontraram ocorrência de anticorpos de $54,8 \%$ para cães e $84,7 \%$ em humanos por meio do teste de aglutinação direta de anticorpos. Como fator de risco foi detectado a ausência de caixa d'água, evidenciando a necessidade de adoção de medidas profiláticas mais adequadas e eficazes de saneamento do local.

Langoni et al. (2012) detectaram 22\% de reagentes pela sorologia para $T$. gondii em 50 cães com neuropatias atendidos no Hospital Veterinário da Universidade Estadual Paulista, Botucatu, SP, Brasil.

No Município de Araçatuba, São Paulo, Bresciani et al. (2007) evidenciaram $25 \%$ de positividade para $T$. gondii em 400 gatos avaliados pela reação de imunoflorescência indireta, havendo maior ocorrência em gatos adultos à idosos. Levantamento sorológico em 200 felinos com acesso a rua em São Luis, Maranhão, apresentaram 50,5\% de anticorpos contra T. gondii por imunofluorescência indireta (BRAGA et al., 2012). 


\section{Associação com Outros Agentes}

A toxoplasmose pode estar associada outras enfermidades, como a erlichiose e cinomose canina (GIRALDI et al., 2002; SILVA et al., 2007, AGUIAR et al., 2012).

Em cães Giraldi et al. (2002) estudou a participação do T. gondii, Neospora caninum e do vírus da cinomose na etiologia de sinais neurológicos em cães em dois grupos de cães atendidos pelo Serviço de Neurologia Animal da Universidade Estadual de Londrina, grupo 1 constituído de 67 animais atendido no período de 1987 a 1990 e grupo 2 com 31 animais atendidos no período de 2000 a 2001. Os resultados da sorologia para $T$. gondii foram de $82,5 \%$ e $35,4 \%$, respectivamente. Lesões histopatológicas compatíveis com o vírus da cinomose foram observadas em animais dos dois grupos, a ocorrência desta doença nos grupos 1 e 2 foi de $67,16 \%$ e $54,83 \%$, respectivamente. A neosporose não foi diagnosticada em nenhum animal estudado.

Em gatos, estudos realizados registraram que a infecção por Toxoplasma pode estar associada a doenças imunossupressoras como o vírus da imunodeficiência felina (FIV) e o vírus da leucemia felina (FeLV) prejudicando a resposta do organismo a infecção. A FIV tem sido associada com a coinfecção do $T$. gondii promovendo a reativação da toxoplasmose latente, resultando em nova liberação de oocistos nas fezes (LUCAS et al., 1998; DORNY et al., 2002, AKHTARDANESH et al., 2010).

Nesta mesma espécie animal, no município de Andradina SP, Brasil, Coelho et al. (2011) constataram que a toxoplasmose não está relacionada a imunossupressão ou a coinfecções por Leishmania spp., mas provavelmente à infecção pós-natal em associação ao tipo de dieta e o convívio ratos.

Por sua vez, Sobrinho et al. (2012) constataram que gatos que residiam em área endêmica para leishmaniose visceral são propensos a possuírem como coinfecção o FIV, mas não $T$. gondii.

\section{Modelos de Infecção Experimental}

Aborto espontâneo e morte fetal tem sido observados durante a gestação de fêmeas caninas gestantes infectadas com oocistos, cistos e taquizoitos e T. gondii é agente etiológico reconhecido de falhas reprodutivas na espécie canina (BRESCIANI et al., 1999, 2001, 2009). Arantes et al. (2009) descreveram a presença de $T$. gondii no sêmen, testículos e epidídimo em cães machos com toxoplasmose experimental. Sete dias após a inoculação de amostras seminais positivas para o referido parasito, cadelas com titulação negativa apresentaram conversão sorológica. Reabsorção fetal também foi evidenciada durante a gestação e cistos toxoplasmicos foram encontrados no encéfalo dos filhotes, confirmando a transmissão sexual desta infecção.

\section{Aspectos Clínicos e Patogênicos da Toxoplasmose em Animais de Companhia}

As manifestações clínicas da toxoplasmose são muito variadas e comuns a diversas enfermidades, com envolvimento de vários órgãos e sistemas (CORRÊA; CORRÊA, 1992). O tipo e magnitude da sintomatologia clínica dependem da localização e grau de lesão tecidual, que se deve à ocorrência de necrose determinada pelo caráter intracelular do parasito (CORRÊA; CORRÊA, 1992). O sistema nervoso, pulmões, fígado, tecido muscular esquelético e os olhos são sítios de replicação do protozoário durante a infecção (DUBEY; LAPPIN, 2006). Embora uma grande quantidade dos animais de companhia sejam sorologicamente positivos para toxoplasmose, poucos animais desenvolvem sinais clínicos da doença (LAPPIN, 2004; DUBEY; LAPPIN, 2006). Conforme Swinger, Shmidt e Dubielzig (2009) presume-se que a manifestação clínica da doença ocorra por um déficit da imunidade local ou sistêmica do organismo do hospedeiro, de modo que pacientes imunossupremidos podem apresentar a infecção primária ou recorrente. 
Gatos com a infecção pré-existente de FIV manifestam a toxoplasmose de forma mais grave, quando infectados, apresentando supressão de linfócitos CD4+ e CD8+, bem como redução da expressão de interleucinas (IL-2, IL-6, FNT- $\gamma$ ), quando comparados com gatos que possuem apenas toxoplasmose (DUBEY; LAPPIN, 2006).

Felídeos muitas vezes, estão subclinicamente infectados no momento em que estão liberando os oocistos de $T$. gondii. Em razão do rápido desenvolvimento de imunidade a disseminação do oocisto ocorre somente de sete a quatorze dias, no caso da ocorrência de diarréia, a mesma é de curta duração (dias) e envolve o intestino delgado. Quanto a liberação de oocistos nas fezes, gatos com toxoplasmose e com coinfecções como a do FIV ou FeLV eliminam oocistos na quantidade e período similar aos gatos com toxoplasmose sem estes tipos de coinfecção. A manifestação clínica da toxoplasmose em felinos é geralmente polissistêmica, sendo a uveíte e a febre os achados mais comuns (LAPPIN, 2002, 2004). De acordo com Akhtardanesh et al. (2010) gatos positivos para FeLV apresentam maior risco de coinfecção com $T$. gondii, manifestando anemia e prostação.

Conforme Souza (2003) no exame oftalmológico de gatos com toxoplasmose quando estudados à microscopia de luz, pode-se constatar que o agente não somente invade o trato uveal, bem como a retina e o nervo óptico podem estar comprometidos, logo os sinais oftalmológicos da toxoplasmose podem incluir além da uveíte, a neurite óptica e a retinocoroidite com deslocamento retiniano exsudativo. Das causas de uveíte endógena sistêmica em gatos, o $T$. gondii, é um dos agentes de maior importância, podendo resultar em uveíte anterior ou posterior podendo ser unilateral ou bilateral. A uveíte pode ser induzida diretamente por citólise, via replicação intra-ocular de taquizoítos ou através de fenômenos imunogênicos indiretos resultantes de antígenos ou de complexos antígeno-anticorpo que são depositados ou formados no olho (LAPPIN, 2004). A toxoplasmose ocular pode ocorrer em gatos sem comprometimento sistêmico, podendo ser observado iridociclite, irite, coriorretinite, flare aquoso, precipitados ceráticos, luxação de cristalino, glaucoma e descolamento de retina, e estas alterações podem ocorrer isoladamente ou concomitantes (DUBEY; LAPPIN, 2006).

Abreu etal. (2002) descreveram no sistema ocular através da retinografia áreas de hiperrefletividade, edema de pupila, edema perivascular temporal, exsudato peripapilar bilaterial e hipopigmentação em cães que foram submetidos a infecção experimental por diferentes cepas de $T$. gondii.

No sistema reprodutor da fêmea o $T$. gondii ocasionalmente causa abortamento em gatas e em cadelas, a maioria das fêmeas infectadas pelo agente é carreadora assintomática, entretanto em condições de sistema imune debilitado podem apresentar aborto no início da gestação, devido a placentite e a má formação fetal (BRESCIANI et al., 2001; LAPPIN, 2004; ARANTES et al., 2009; SAKAMOTO et al., 2009).

Em gatos, filhotes que foram infectados por via transplacentária ou durante a lactação, podem apresentar processos inflamatórios que acometem o fígado, pulmões e o sistema nervoso central, o que reflete clinicamente como uveíte, letargia, depressão, ascite, encefalite, hipotermia e morte súbita. Em adultos com a infecção primária ou recorrente, são descritos anorexia, letargia, dispnéia, pneumonia, febre intermitente, emaciação, vômito, diarréia, hiperestesia, marcha rígida, claudicação, déficit neurológico, dermatite e morte (BRESCIANI et al., 2001; DUBEY; LAPPIN, 2006).

Conforme Smart, Downey e Stockdale (1973) e Harvey e Greeffydd-Jones (2010) a icterícia, colangite, ascite, hepatite e pancreatite podem estar associadas ao comprometimento hepatobiliar promovido pelo $T$. gondii em gatos, bem como as diferentes formas de apresentação do complexo colangite felino podem estar relacionados a toxoplasmose, pois, o T. gondii pode promover acúmulo periportal de células mononucleares. 
Em um estudo realizado por Dubey e Carpenter (1993), com 100 gatos com o diagnóstico de toxoplasmose confirmado pelo exame histopatológico, foi observado em 97,7\% dos casos, infecção pulmonar, 96,4\% com comprometimento de sistema nervoso central, 93,3\% com hepatite, $84,4 \%$ com pancreatite, $86,4 \%$ com alterações no sistema cardiovascular e $81,5 \%$ oftalmológicas.

Manifestações tegumentares também podem estar associadas à toxoplasmose, Park et al. (2007), relataram um caso de uma gata que apresentou em uma glândula mamária, um nódulo de aproximadamente $3 \mathrm{~cm}$ de diâmetro. $\mathrm{O}$ exame histopatológico do mesmo demonstrou paniculite necrosante piogranulomatosa, vasculite e mastite com agrupamentos de taquizoítos sugestivos de $T$. gondii, sendo confirmada a infecção por $T$. gondii pela PCR.

Dubey e Prowell (2012) relataram a ocorrência de oocistos ( 6 milhões em uma amostra) de $T$. gondii nas fezes em um gato macho de 6 anos de idade com letargia, anorexia, febre e diarréia. Com titulação positiva para $T$. gondii de 1:800. Foi realizado a genotipagem de $T$. gondii, sendo evidenciada o do tipo I, sendo o primeiro isolamento do parasito caracterizado geneticamente em um gato com toxoplasmose adquirida nos EUA.

Em cães, a manifestação da doença pode ser subclínica ou clínica, demonstrada por febre, linfadenopatia, (BRESCIANI et al., 2001). D'Ark Moretti et al. (2002) ressalta a necessidade da inclusão do diagnóstico diferencial da toxoplasmose em cães com sintomas do sistema respiratório e/ ou nervoso, em relação a outras enfermidades que acometem estes sistemas, como a cinomose. De acordo com Silva et al. (2007) são comuns pneumonia e manifestações neurológicas em cães com toxoplasmose.

Em um estudo realizados por Abreu et al. (2001) em cães com toxoplasmose experimentalmente, foi observado aumento de linfonodos e alterações oftálmicas. Conforme D'Ark Moretti et al. (2002) os sinais clínicos generalizados em cães são observados com maior frequência em filhotes, ou seja em animais com menos de um ano de idade. No entanto, nesta faixa etária os principais sinais clínicos são neuromusculares. Em infecções decorrentes da ingestão de cistos teciduais ou oocistos, ocorre inapetência, dispnéia, tosse, diarréia, vômito, hematoemese, esplenomegalia e ocasionalmente hepatomegalia, estas manifestações são decorrentes da ação dos taquizoítos, principalmente no sistema digestório, sistema respiratório e nos órgãos linfóides associados (SMART; DOWNEY; STOCKDALE, 1973). O envolvimento linfático provoca linfadenopatia, referida como a manifestação clínica mais frequênte na toxoplasmose adquirida nos cães (SMART; DOWNEY; STOCKDALE, 1973; DUBEY; LAPPIN, 2006).

O T. gondii induz necrose pulmonar, levando a pneumonia e dispnéia, embora em muitos casos, a pneumonia seja decorrente da coinfecção com outros agentes, como já citado o vírus da cinomose. As lesões pulmonares promovidas pelo $T$. gondii são variadas, multifocais com necrose intersticial com proliferação de pneumócitos do tipo II e infiltrado de macrófagos e neutrófilos (McGAVIN; ZACHARY, 2012).

As lesões musculares por $T$. gondii determinam hiperestesia à palpação, marcha rígida e claudicação. No cão arritmias e insuficiência cardíaca também podem se desenvolver devido ao envolvimento miocárdico (LAPPIN, 2005; DUBEY; LAPPIN, 2006).

Os sinais nervosos da toxoplasmose dependem da localização do parasito no cérebro, cerebelo e medula espinhal. A multiplicação do agente nestes locais leva a episódios convulsivos, déficits de nervos cranianos, ataxia, tremores, paresias e paralisias (DUBEY; LAPPIN, 2006). No sistema nervoso a capacidade de manutenção do $T$. gondii está relacionada à impermeabilidade da barreira hematoencefálica aos anticorpos circulantes (CARVALHO, 2007). 
Mudanças de comportamento, eventualmente podem ocorrer com desenvolvimento da toxoplasmose, como a apatia ou agressividade. Entretanto, os sinais nervosos predominantes da toxoplasmose são paresia e paralisia de membros posteriores (CORRÊA; CORRÊA, 1992; PLUGGE et al., 2011). Diversos estudos foram realizados em cães com toxoplasmose naturalmente adquirida e foram observados: paraparesia espática, paraplegia flácida, paraplegia espática, ataxia com tremor de intenção, hemiparesia, lesões estas resultantes do comprometimento de nervos espinhais, medula espinhal, cerebelo e córtex unilateral (AVERILL; LAHUNTA, 1971; NESBIT; LOURENS; WILLIAMS, 1981; SUTER et al., 1984; PLUGGE et al., 2011).

Conforme McGavin e Zachary (2012), na condição de comprometimento do sistema nervoso central, o $T$. gondii ultrapassa a barreira hematoencefálica, por meio intracelular, infectando as células endoteliais do sistema nervoso central, principalmente os capilares, promovendo assim, a vasculite e o edema, em evolução da lesão tecidual pode ocasionar hemorragia e necrose. Desse modo, a sintomatologia de comprometimento do sistema nervoso pode ser variada, pois depende da idade do animal, espécie e áreas afetadas no sistema nervoso central pelo agente.

Bresciani et al. (1999, 2001) induziram a toxoplasmose de forma experimental em oito cadelas gestantes, e constataram febre, corrimento nasal, lacrimejamento, prostação, linfadenopatia, parto prematuro, abortamento e morte fetal.

O comprometimento ocular promovido pelo T. gondii é caracterizado pelo seu tropismo por tecido neural, como a retina. A lesão se desenvolve com inflamação, afetando as diferentes camadas da mesma e posteriormente a coróide. Com a progressão do dano ocular, ocorre a formação de intenso processo inflamatório granulomatoso, com cistos intracelulares do protozoário. Necrose com neovascularização do espaço sub-retiniano e da coróide, bem como processo inflamatório local envolvendo a retina e seu epitélio pigmentar são danos promovidos pelos taquizoítos (GAZZINELLI et al., 1994).

Abreu et al. (2001) estudou cães com toxoplasmose ocular experimental e constataram no exame de fundo de olho alterações como áreas de hiperrefletividade, papilema, edema perivascular e vitreíte Conforme D'Ark Moretti et al. (2002) e Swinger, Shmidt e Dubielzig (2009) a toxoplamose ocular em cães é rara, mas as lesões incluem ceratoconjuntivite seca, uveíte anterior, iridociclite, hiperplasia do epitélio ciliar, retinite, coroidite, miosite extra-ocular, esclerite, episclerite, neurite óptica e massas corneais e conjuntivais.

A manifestação cutânea da toxoplasmose tem sido relatada em humanos imunossuprimidos e raramente em gatos. Webb et al. (2005) descreveram o caso de um cão, com histórico de uso de terapia imunossupressora para o controle de anemia imunomediada, com manifestação cutânea de dermatite pustular alopécica associada a toxoplasmose, acredita-se que a terapia imunossupressora predispôs o animal a este tipo de manifestação clínica. Similar ao relato de Hoffman et al. (2012), que descreveram dois casos de toxoplasmose com manifestação clínica cutânea em cães que passaram por tratamentos imunossupressores, o que supõe ter ocorrido a reativação da infecção latente por $T$. gondii. As lesões eram caracterizadas por múltiplos nódulos alopécicos ulcerados com material purulento com dermatite pustular generalizada.

Nos animais domésticos e nas mulheres gestantes, expostos pela primeira vez à infecção do $T$. gondii, justamente durante a gestação, pode ocorrer o desenvolvimento de fetos com doença congênita, mortalidade e reabsorção embrionária, mumificação, abortos ou nascimento de filhotes doentes. As lesões predominantes são encontradas no sistema nervoso central, no entanto outros sistemas também podem ser comprometidos. A retinocoroidite é uma lesão 
frequente na toxoplasmose congênita. A retina tornase inflamada e necrótica e a camada pigmentada rompe-se por infiltração de células inflamatórias; finalmente forma-se o tecido de granulação que invade o humor vítreo (URQUHART et al., 1998).

Bresciani et al. $(1999,2001)$ estudaram filhotes de cadelas com toxoplasmose experimental, e constataram que estes filhotes nasceram aparentemente saudáveis, mesmo sendo sorologicamente positivos, com títulos de anticorpos de 1:64 até 1:256, neste experimento apenas um dos neonatos se mostrou debilitado. Neste mesmo estudo, foram isolados nas amostras de saliva, leite e urina, o parasito nos animais estudados.

Nos achados de necropsias em pequenos animais com toxoplasmose, as lesões macroscópicas descritas são: necrose cerebral, descoloração do tecido nervoso, necrose e atrofia cerebelar, necrose pulmonar, necrose hepática e de linfonodos mesentéricos (DUBEY; LAPPIN, 1998). Na necropsia, podem ser observados cistos de bradizoítos nos sistema nervoso, sistema respiratório e linfático (ARANTES et al., 2009).

Bjerkãs e Presthus (1989) estudaram as alterações no sistema nervoso central de 7 cães com toxoplasmose, através da microscopia de luz, imuno-histoquímica e microscopia eletrônica. Taquizoítos foram evidenciados em vacúolos parasitóforos em neurônios, astrócitos, macrófagos e em fibroblastos, promovendo necrose e formação de granulomas. Na medula espinhal a substância cinzenta foi seriamente comprometida enquanto na substância branca apenas se evidenciou focos de inflamação.

As alterações histopatológicas mais comuns no sistema nervoso central incluem: encefalite, meningoencefalomielite não supurativa, necrose, malácia e gliose, com eventual comprometimento de nervos periféricos (DUBEY; LAPPIN, 1998).

Carvalho (2007) analisou a morfologia e morfometria da medula espinhal de 10 cães soropositivos para toxoplasmose assintomáticos, constatando que não houve alterações morfológicas visíveis, pela microscopia de luz quando comparados a morfologia da medula espinhal do grupo de cães normais, entretanto, os resultados morfométricos demonstraram que há diferença no tamanho e estrutura dos neurônios, ocorrendo aumento e perda do formato estrelado nos animais soropositivos, provavelmente devido a um processo de edema celular.

Nos animais domésticos o $T$ gondii, também é considerado um agente provedor de hipersensibilidade tipo IV, podendo formar granulomas (McGAVIN; ZACHARY, 2012).

Conforme Lappin (2004) e Carvalho (2007), não existem alterações clinicopatológicas ou de diagnóstico por imagem patognomônicas de toxoplasmose em cães e gatos, a confirmação do diagnóstico depende do isolamento do parasito, demonstração histopatológica do organismo nas lesões e de sorodiagnóstico positivo.

\section{Diagnóstico da Toxoplasmose em Animais de Companhia}

Achados no perfil hematológico e bioquímico sérico

$\mathrm{Na}$ toxoplasmose aguda, em cães e gatos pode ser evidenciada anemia não regenerativa no perfil eritrocitário, no perfil leucocitário, a leucocitose com neutrofilia, leucopenia ou linfocitose podem estar presentes, bem como monocitose e eosinofilia são achados comuns (ABREU et al., 2001; DUBEY; LAPPIN, 2006).

No perfil hepático quando em situações de comprometimento tecidual a toxoplasmose pode promover hipoproteinemia, hipoglobulinemia, aumento das atividades enzimáticas séricas de alanina amino transferase (ALT), fosfatase alcalina (FA) e aumento nos níveis séricos de bilirrubina (CORRÊA; CORRÊA, 1992; BRESCIANI et al., 2001), contudo, Abreu et al. (2001) não observou comprometimento hepático em cães após inoculação de cepas do parasito. De acordo com Dubey e 
Lappin (2006) hiperglobulinemia pode ocorrer em gatos com toxoplasmose crônica.

As lesões musculares por $T$. gondii podem estar associadas ao aumento da atividade sérica enzimática de creatinina quinase (DUBEY, 1998).

Cães ou gatos que desenvolvem com o curso da doença, a pancreatite podem apresentar aumento sérico de amilase e lipase, bem como também são descritos a redução do cálcio total sérico nesta condição (DUBEY; LAPPIN, 2006).

\section{Achados na Citologia}

A forma ativa do $T$. gondii, os taquizoítos durante o desenvolvimento da enfermidade, podem ser detectados pela citologia de amostras de tecidos e fluidos corporais, como: no sangue, no líquido cefalorraquidiano, no peritônio, e de amostras de lavados broncoalevolar. Os taquizó́tos também podem ser isolados a partir de amostras do líquido ascítico ou de efusão pleural (BROWNLEE; SELLON, 2001; DUBEY; LAPPIN, 2006).

Quando em situações de manifestação neurológica, em decorrência da doença, podem ser evidenciado na análise do líquido cefalorraquidiano, o aumento da concentração de proteína, e/ou a presença de eosinófilos, que sugerem a migração do parasito para o sistema nervoso, sendo indicado uma melhor investigação diagnóstica para o $T$. gondii (SARMENTO et al., 2000).

\section{Coproparasitológico}

O diagnóstico pode ser realizado pela presença de oocistos nas fezes do hospedeiro definitivo, no exame parasitológico, sendo indicado o método de centrífugo-flutuação ou método de Sheather. Entretanto a prevalência de oocistos nas fezes é baixa, pois os oocistos são liberados no período de uma duas semanas durante a evolução clínica da enfermidade, com a ocorrência de diarréia, tornando o oocisto um achado ocasional no exame parasitológico de fezes, gatos assintomáticos também podem eliminar os oocistos (DUBEY; LAPPIN, 2006; MONTEIRO, 2010).

Os oocistos de T.gondii são morfologicamente indistinguíveis de outros coccídios, como Sarcocystis, Frenkelia, Besnoitia e estes só podem ser diferenciados por técnicas de biologia molecular (DUBEY; LAPPIN, 2006).

\section{Diagnóstico por Imagem}

Em gatos com a evolução aguda da enfermidade no exame radiográfico de tórax são descritos padrão alveolar intersticial difuso com distribuição lobar, podendo ser observado em animais severamente comprometidos um padrão difuso e homogêneo devido à coalescência alveolar. No exame radiográfico abdominal são descritos massas no intestino, aumento de linfonodos mesentéricos e ascite. No exame ultrassonográfico abdominal é descrita vizibilização do aumento de tecidos ou de órgãos, sugestivo de formação de granulomas. A mielografia, tomografia computadorizada e ressonância magnética podem detectar comprometimento do sistema nervoso central (DUBEY; LAPPIN, 2006).

\section{Testes Sorológicos}

Uma vez infectados, os animais podem abrigar bradizoítos nos tecidos, o que estimula em longo prazo uma resposta imune humoral. A detecção de anticorpos contra o $T$. gondii, por reação de imunofluorescência indireta, assim como pelo teste de aglutinação direta, teste de hemaglutinação e ELISA, são métodos recomendados para o diagnóstico e levantamento epidemiológico desta zoonose (ZHANG et al., 2001; DUBEY; LAPPIN, 2006). 


\section{Outros Recursos em Diagnóstico}

O exame histopatológico associado a técnica de imuno-histoquímica, e ambos em associação com a PCR, têm sido amplamente utilizados no diagnóstico da infecção (BRESCIANI et al., 2009).

\section{Alternativas Terapêuticas}

Nos casos de toxoplasmose em animais de companhia, o cloridrato de clindamicina administrado via oral ou por via parenteral, é eficaz para o tratamento da doença polissistêmica e pode encurtar o período de eliminação dos oocistos no caso dos gatos (LAPPIN, 2004; SWINGER; SHMIDT; DUBIELZIG, 2009).

O cloridrato de clindamicina possui boa absorção intestinal, sendo efetiva e demonstrando a melhora clínica do paciente entre 24 e 48 horas após o início da administração do fármaco, sendo descritos neste período, retorno ao apetite, desaparecimento da hiperestesia e febre, seguindo por semanas o tratamento é relatado o restabelecimento do funcionamento de nervos cranianos e nervos espinhais, quando comprometidos, bem como a resolução da polimiosite, nos casos de alterações oftalmológicas são descritos a melhora clínica após uma semana de uso do fármaco. Desse modo, o cloridrato de clindamicina possui ação satisfatória na barreira hematoencefálica e na vascularização dos órgãos e tecidos que confere a melhora clínica do paciente, sendo empregada para o controle da toxoplasmose em animais e em humanos, com indicação para o tratamento de fêmeas gestantes (DUBEY; LAPPIN, 2006).

Em altas doses em gatos o cloridrato de clindamicina pode provocar irritação local no sistema digestório, ocorrendo efeitos colaterais como anorexia, vômitos e diarréia (DUBEY; LAPPIN, 2006).

O uso de glicocorticóides é contra indicado, pois podem exacerbar a manifestação da doença quando comprometimento sistêmico, entretanto, no caso de lesão no órgão da visão, o uso tópico do fármaco associado com o cloridrato de clindamicina confere bom resultado (DUBEY; LAPPIN, 2006; HARVEY; GREEFFYDD-JONES, 2010).

Quando comprometimento de medula óssea é recomendado a suplementação com ácido fólico (DUBEY; LAPPIN, 2006).

Estudos in vitro realizados por Giraldi et al. (2002) verificou-se que as sulfonamidas, inibidores do dihidrofosfato redutase e timodilato sintetase e antibióticos ionóforos (lasolocida, narasina e salinomicina), macrolídeos, tetraciclinas e lisonaminas tem ação sobre taquizoítos e drogas como metronidazol, paramomicina e roxarsona exercem pouca ou nenhuma atividade sobre estas formas evolutivas de multiplicação rápida do agente.

A combinação de sulfametaxol-trimetoprima tem demonstrado efeitos satisfatórios no controle da toxoplasmose, principalmente no tratamento da toxoplasmose ocular em humanos (DUBEY; LAPPIN, 2006).

Papich (2009) descreveu que a combinação sulfadiazina-trimetoprima e a combinação de sulfametaxol-trimetoprima são eficazes no tratamento e no controle da toxoplasmose em pequenos animais.

Barbosa et al. (2012) realizaram estudos in vitro e in vivo em modelos experimentais, utilizando a enrofloxacina no tratamento da toxoplasmose, que se mostrou eficaz sem muitos efeitos colaterais, podendo ser uma importante alternativa no tratamento da manifestação clínica da toxoplasmose.

A doxiciclina e a minoclina tem demonstrado eficácia em estudos realizados experimentalmente in vitro e in vivo em camundongos e em humanos, quando em comprometimento de sistema nervoso central (DUBEY; LAPPIN, 2006).

O Ponazurilé um composto anticoccídio utilizado no tratamento de equinos, e apesar de seu uso não ser aprovado em cães, Swinger, Shmidt e Dubielzig (2009) provaram que este composto pode ser 
efetivo no tratamento da toxoplasmose, sugerindo mais estudos sobre o fármaco em pequenos animais.

No homem, o uso do Atovaquone pode ser uma opção nos casos de pacientes intolerantes a sulfadiazina ou clindamicina, principalmente em portadores da síndrome da imunodeficiência adquirida com comprometimento de sistema nervoso central (SCHÖLER et al., 2001). Este fármaco têm demonstrado eficácia na ação dos cistos de $T$. gondii, entretanto o seu uso é exclusivamente experimental (DUPOUY-CAMET, 2004).

\section{Medidas de Profilaxia e Controle da Toxoplasmose}

Deve-se realizar limpeza diária em gatis e a remoção adequada das fezes, pois os oocistos necessitam de pelo menos 24 horas para esporular e se tornarem infectantes. Recomenda-se evitar o hábito de coprofagia observado em alguns animais, bem como o controle de insetos e roedores no ambiente. Não consumir e não fornecer aos animais a carne crua ou leite cru de cabra, sendo indicado o uso de produtos ou alimentos comerciais disponíveis (MONTEIRO, 2010).

Condutas de higiene pessoal devem ser rigorosamente seguidas, não devendo ser consumida e nem fornecida aos animais à água de lagos, poços e rios que não passem por um tratamento prévio. $\mathrm{O}$ acesso de cães e gatos em reservatórios de água deve ser proibido, bem como em laticínios e frigoríficos (MONTEIRO, 2010).

\section{Considerações Finais}

A toxoplasmose trata-se de uma zoonose de distribuição mundial, que promove sintomatologia clínica variada, severa e fatal, sem achados clinicopatológicos ou patognomônicos específicos, constituindo assim, em um desafio clínico ao médico veterinário, principalmente quando no comprometimento do sistema nervoso e do órgão da visão. Para o clínico de pequenos animais, são considerados como recursos em auxílio diagnóstico, o exame oftalmológico e os exames laboratoriais de rotina, que podem sugerir a ação local e/ou sistêmica do protozoário. O exame citológico de fluídos corporais e de parâmetros avaliados na análise do líquido cefalorraquidianos também são ferramentas em diagnóstico que podem sugerir ou mesmo comprovar a presença do $T$. gondii. A utilização de métodos de diagnóstico por imagem auxilia na compreensão e entendimento do real comprometimento tecidual local ou sistêmico promovido pelo parasito, sendo importante para justificar as manifestações clínicas demonstradas pelo paciente. No momento, os testes sorológicos são métodos recomendados para o diagnóstico definitivo e levantamento epidemiológico desta zoonose. Estudos estão sendo desenvolvidos com diferentes fármacos para obtenção de novas alternativas terapêuticas para a toxoplasmose, entretanto, atualmente o cloridrato de clindamicina, a sulfadizina-trimetoprima e a sulfametaxoltrimetoprima apresentam efeitos satisfatórios no tratamento e controle da toxoplasmose em pequenos animais.

\section{Referências}

ABREU, C. B.; NAVARRO, I. T.; SALARIN, M. R. S.; BRACARENSE, A. P. F. R.L.; MARANA, E. R. M.; TRAPP, S. M.; FUGINAKA, C. A.; PRUDÊNCIO, L. B.; MATOS, M. R.; TSUTSUI, V. S. Aspectos clínicos, patológicos e sorológicos da toxoplasmose experimental em cães jovens. Semina: Ciências Agrárias, Londrina, v. 22, n. 2, p. 123-130, 2001.

ABREU, C. B.; NAVARRO, I. T.; REIS, A. C. F.; SOUZA, M. S. B.; MACHADO, R.; MARANA, E. R. M.; PRUDÊNCIO, L. B.; MATTOS, M. R.; TSUTSUI, V. S. Toxoplasmose ocular em cães jovens inoculados com Toxoplasma gondii. Ciência Rural, Santa Maria, v. 32, n. 5, p. 807-812, 2002.

AGUIAR, D. M.; AMUDE, A. M.; SANTOS, L. G. F.; RIBEIRO, M. G.; UENO, T. E. H.; MEGID, J.; PAES, A. C.; ALFIERI, A. F.; ALFIERI, A. A.; GENNARI, S. M. Canine distemper vírus and Toxoplasma gondii co-infection in dogs with neurological signs. Arquivos 
Brasileiros de Medicina Veterinária, Belo Horizonte, v. 64, v. 1, p. 221-224, 2012.

AKHTARDANESH, B.; ZIAALI, N.; SHARIFI, H.; REZAEI, S. Feline immnodeficiency vírus, feline leukemia vírus and Toxoplasma gondii stray and household cats in Keman-Iran: Seroprevalence and correlation with clinical and laboratory findings. Research in Veterinary Sciense, London, v. 89, n. 2, p. 306-310, 2010.

ARANTES, T. P.; LOPES, W. D.; FERREIRA, R. M.; PIERONI, J. S.; PINTO, V. M.; SAKAMOTO, C. A.; COSTA, A. J. Toxoplasma gondii: evidence for the transmission by sêmen in dogs. Experimental Parasitology, San Diego, v. 123, n. 2, p. 190-194, 2009.

ARAÚJO, D. A.; SILVA, A. V.; ZANETTE, D. F.; SILVA, D. R.; CORREA, N. A. B.; VELASQUEZ, L. G.; PINTO-NETO, A. Investigação dos fatores associados à infecção pelo $T$. gondii em cães e seres humanos de Porto Figueira (PR). Revista Medicina Veterinária e Zooctecnia, Botucatu, v. 18, n. 1, p. 98-111, 2011.

AVERILL, D. R.; LAHUNTA, A. Toxoplasmosis of the canine nervous system: Clinicopathological Findings in Four cases. Journal American Veterinary Medical Association, Schaumburg, v. 159, n. 9, p. 11-34, 1971.

BARBOSA, B. F.; GOMES, A. O.; FERRO, E. A.; NAPOLITANO, D. R.; MINEO, J. R.; SILVA, N. M. Enrofloxacin in able to control Toxoplasma gondii infection in both in vitro and in vivo experimental models. Veterinary Parasitology, Amesterdam , v. 187, n. 1-2, p. 44-52, 2012.

BICHARA, C. N. C. Perfil Epidemiológico da toxoplasmose humana na área metropolitana de Belém/ PA - a experiência no serviço de parasitologia do Instituto Evandro Chagas. 2001. Dissertação (Mestrado em Ciências Biológicas) - Universidade Federal do Pará. Museu Paraense Emílio Goeldi e Empresa Brasileira de Pesquisa Agropecuária, Belém.

BJERKÃS, I.; PRESTHUS, J. The neuropathology in toxoplasmosis-like infection caused by a newly recognized cyst-forming sporozoon in dogs. Acta Pathologica, Microbiologica et Immunologica, Scandinavia, v. 97, n. 1-6, p. 456-468, 1989.

BORGES, A. S.; FIGUEIREDO, J. F. C. Detecção de imunoglobulinas IgG, IgM e IgA anti-Toxoplasma gondii no soro, líquor, e saliva de pacientes com Síndrome da Imunodeficiência Adquirida e Neurotroxoplasmose. Arquivos Neuropsiquiatria, São Paulo, v. 62, n. 4, p. 1033-1037, 2004.
BRAGA, M. S. C.; ANDRÉ, M. R.; JUSI, M. M. G.; FRESCHI, C. R.; TEIXEIRA, M. C. A.; MACHADO, R. Z. Ocurrence of anti-Toxoplasma gondii and antiNeospora caninum antibodies in cats with outdoor acess in São Luís, Maranhão, Brazil. Revista Brasileira de Parasitologia, Jaboticabal, v. 21, n. 2, p. 107-111, 2012.

BRESCIANI, K. D. S.; COSTA, A. J.; NUNES, C. M.; SERRANO, A. C. M.; MOURA, A. B.; STOBBE, N. S.; PERRI, S. H. V.; DIAS, R. A.; GENNARI, S. M. Ocorrência de anticorpos contra Neospora caninum e Toxoplasma gondii e estudo de fatores de risco em cães de Araçatuba (SP). ARS Veterinária, Jaboticabal, v. 23, n. 1, p. 40-46, 2007.

BRESCIANI, K. D. S.; COSTA, A. J.; TONIOLLO, G. H.; SABATINI, G. A.; MORAES, F. R.; PAULILLIOS, A. C.; FERRAUDO, A. S. Experimental toxoplasmosis in pregnant biches. Veterinary Parasitology, Amsterdam, v. 86, n. 2, p. 143-145, 1999.

BRESCIANI, K. D. S.; GENNARI, S. M.; SERRANO, A. C. M.; RODRIGUES, A. A. R.; UENO, T.; FRANCO, L. G.; PERRI, S. H. V.; AMARANTE. Antibodies to Neosporoa caninum and Toxoplasma gondii in domestic cats from Braszil. Parasitology Research, New York, v. 100, n. 281-285, p. 281-285, 2007.

BRESCIANI, K. D. S.; SOUZA, A. P.; SARTOR, A. A.; BELLATO, V.; TEIXEIRA, E. B.; PISETTA, G. M. JUNIOR, H. A. Ocorrência de anticorpos e fatores de risco para infecção por Toxoplasma gondii em cães, nas cidades de Lages e Balneário Camboriú, Santa Catarina, Brasil. Revista Brasileira de Parasitologia Veterinária, Jaboticabal, v. 18, n. 3, p. 52-56, 2009.

BRESCIANI, K. D. S.; TONIOLLO, G. H.; COSTA, A. J. C.; SABATINI, G. A.; MORAES, F. R. Clinical, parasitological and obstetric observations in pregnant bitches with experimental toxoplasmosis. Ciência Rural, Santa Maria, v. 31, n. 6, p. 1039-1043, 2001.

BRESCINAI, K. D. S.; GALVÃO, A. L. B.; VASCONCELLOS, A. L.; GONGES, J. F.; SANTOS, T. R.; VIOL, M. A.; AQUINO, M. C. C.; NAVARRO, I. T. Epidemiology and control of toxoplasmosis in cats. Toxoplasma gondii: Prevalence in Humans and Animals, Genetic Structure and Role in Disease Distribution. Nova Publishers, New York, v. 23, n. 1, p. 95-108, 2013.

BROWNLEE, L.; SELLON, R. K. Diagnosis of naturally ocorring toxoplasmosis by bronchoalveolar lavage in cat. Journal of the American Hospital Association, Schaumburg.v. 37, n. 3, p. 251-255, 2001.

CÃNON-FRANCO, W. A.; BERGAMASCHI, D. P.; LABRUNA, M. B.; CAMARGO, L. M.; SILVA, J. 
C.; PINTER, A.; GENNARI, S. M. Ocurrence of antiToxoplasma gondii antibodies in dogs in the urban área of Monte Negro, Rondônia, Brazil. Veterinary Research, London, v. 28, n. 2, p. 113-118, 2004.

CARVALHO, A. C. F. Toxoplasmose: morfologia e morfometria da medula espinhal de cães soropositivos assintomáticos. 2007. Tese (Doutorado em Medicina Veterinária) - Faculdade de Ciências Agrárias e Veterinárias, Universidade Estadual Paulista, Jaboticabal.

COELHO, W. M.; AMARANTE, A. F. T.; APOLINÁRIO, J. C.; COELHO, N. M. D.; LIMA, V. M. F.; PERRI, S. H. V.; BRESCIANI, K. D. S. Seroepidemiology of Toxoplasma gondii, Neospora coninum, and Leishmania spp. Infections and risck factors for cats from Brazil. Parasitology Research, New York, v. 109, n. 1009-1013, p. 1009-1013, 2011.

CORREAA, W. M.; CORRÊA, C. N. M. Toxoplasmose. In: _. Enfermidades infecciosas dos mamíferos domésticos. Rio de Janeiro: Medsi, 1992. p. 757-766.

D'ARC-MORETTI, L.; UENO, T. E.; RIBEIRO, M. G.; AGUIAR, D. M.; PAES, A. C.; PEZERICO, S. B.; SILVA, A. V. Toxoplasmose em cães co-infectados com o vírus da cinomose. Semina: Ciências Agrárias, Londrina, v. 23, n. 1, p. 85-91, 2002.

DORNY, P.; SPEYBROECK, N.; VERSTRAETE, S.; DE BECKER, A.; BERKEVENS, D.; VERCRUYSSE, J. Serological survery of Toxoplasma gondii, feline immunodeficiency virus and feline leukaemia virus in urban stray cats in Belgium. Veterinary Record, London, v. 151, n. 21, p. 626-629, 2002.

DUBEY, J. P. Toxoplasmosis. Journal of the American Veterinary Medical Association, Schaumburg, v. 189, n.2, p. 166-170, 1986.

. Duration of immunity to shedding of Toxoplasma gondii oocysts by cats. The Journal of Parasitology, Lawrence, v. 81, n. 3, p. 410-415, 1995.

Re-examination of resistance of Toxoplasma gondii tachyzoites and bradyzoites to pepsin and trypsin digestion. Parasitology, London, v. 116, n. 1, p. 43-50, 1998.

DUBEY, J. P.; CARPENTER, J. L. Histologically confirmed clinical toxoplasmosis in cats: 100 cases (19521990). Journal of the American Hospital Association, Schaumburg, v. 203, n. 11, p. 1556-1566, 1993.

DUBEY, J. P.; GREENE, C. E.; LAPPIN, M. R. Toxoplasmosis and Neosporosis. In: GREENE, C. E. Infectious diseases of the dog and cat. 2. ed. Philadelphia: W. B. Saunders, 1990, p. 818-834.

DUBEY, J. P.; LAPPIN, M. R. Toxoplasmosis and neosporosis. In: GREENE, C. E. Infectious diseases of the dog and cat. 2. ed. Philadelphia: WB Saunders Company, 1998. cap. 90, p. 493-503.

Toxoplasmosis and neosporosis. In: GREENE, C. E. Infectious diseases of the dog and cat. 3. ed. St. Louis: Elsevier, 2006. p. 754-775.

DUBEY, J. P.; LINDSAY, D. S.; HILL, D.; ROMAND, S.; THULLIEZ, P.; KWOK, O. C.; SILVA, J. C.; OLIVEIRA-CAMARGO, M. C.; GENNARI, S. M. Prevalence of contrabodies to Neospora caninum and Sarcocystis neurona in sera of domestic cats from Brazil. The Journal of Parasitology, Lawrence, v. 88, n. 6, p. 1251-1252, 2002.

DUBEY, J. P.; MATTIX, M. E.; LIPSCOMB, T. P. Lesions of neonatally induced toxoplasmosis in cats. Veterinary Pathology, New York, v. 33, n. 3, p. 290-295, 1996.

DUBEY, J. P.; PROWELL, M. Ante-mortem diagnosis diarrhea, oocyst shedding, treatment, isolation and genetic typing of Toxoplasma gondii associated with clinical toxoplasmosis in a naturally infected cat. The Journal Parastiology, Lawrence, v. 5, n. 58, p. 158-160, 2012.

DUPOUY-CAMET, J. New drugs for the treatment of human parasitic protozoa. Parassitologia, Roma, v. 46, n. 1-2, p. 81-84, 2004.

ETHEREDGE, G. D.; MICHAEL, G.; MUEHLENBEIN, M. P.; FRENKEL, J. K. The roles of cats and dogs in the transmission of Toxoplasma gondii infection in Kuna and Embera children in eastern Panama. Revista Pananericana de Salud Pública, Washinngton, v. 16, n. 3, p. 176-186, 2004.

FAUCHER, B.; GARCIA-MERIC, P.; FRANCK, J.; MINODIER, P.; FRANCOIS, P.; GONNET, S.; L'OLLIVIER, C.; PIARROUX, R. Long-term ocular outcome in congenital toxoplasmosis: A prospective cohort of treated children. The Journal of Infection, London, v. 64, n. 1, p. 104-109, 2012.

FERNANDES, M. A.; BATISTA, G. I.; CARLOS, J. C. S.; GOMES, I. M.; AZEVEDO, K. M. L.; SETUBAL, S.; OLIVEIRA, S. A.; VELARDE, L. G. C.; CARDOSO, C. A. A. Toxoplasma gondii antibody profile in HIV -1 infected and uninfected pregnant women and the impact on congenital toxoplasmosis diagnosis in Rio de Janeiro. The Brazilian Journal of Infectious Diseases, Salvador, v. 16, n. 1, p. 170-174, 2012.

FREIRE, R. L.; NAVARRO, I. T.; VIDOTTO, O.; TUDURY, E. A.; VIANNA, C. C. Prevalência de Anticorpos anti-Toxoplasma gondii em cães atendidos no Hospital Veterinário da UEL-PR. Semina: Ciências Agrárias, Londrina, v. 13, n. 1, p. 66-69, 1992. 
FRENKEL, J. K.; DUBEY, J. P.; MILLER, N. L. Toxoplasma gondii in cats: fecal stages identified as coccidian oocysts. Science, New York, v. 6, n. 167, p. 893896, 1970.

FRENKEL, J. K. Toxoplasmosis: parasite, life cycle, pathology and immunology. In: HAMMOND, D. M.; LONG, P. L. (Ed.). The Coccidia: eimeria, isospora, toxoplasma, and related genera. Baltimore: University Park Press, 1973. p. 343-410.

FRENKEL, J. K.; BERMUDEZ, J. E. V. Toxoplasmose. In: VERONESI, R.; FOCACCIA, R. Tratado de infectologia. São Paulo: Atheneu, 2006. p. 1634-1649.

FRENKEL, J. K.; DUBEY, J. P. Rodents as vectors for feline Coccidia, Isospora felis and Isospora rivolta. The Journal of Infectious Disease, Oxford, v. 125, n. 1, p. 69$72,1972$.

FRENKEL, J. K.; PARKER, B. B. An apparent role of dogs in the transmission of Toxoplasma gondii. The probable importance of xenosmophilia. Annals of the New York Academy of Sciences, New York, v. 791, p. 402-407, 1996.

GADEMARTORI, B. G. Toxoplasmose: perfil sorológico em gestantes atendidas em Postos de Saúde do município de Pelotas-RS. 2007. Dissertação (Mestrado em Parasitologia) - Programa de Pós-Graduação em Parasitologia, Universidade Federal de Pelotas, Pelotas.

GAZZINELLI, R. T.; BREZIN, A.; NUSSENBLATT, R. B.; CHAN, C. C.; Toxoplasma gondii: acquired ocular toxoplasmosis in the murine, protective role of TNFalpha and IFN-gamma. Experimental Parasitology, San Diego, v. 78, n. 2, p. 217-219, 1994.

GIRALDI, J. H.; BRACARENCE, A. P. F. R.; VIDOTTO, O.; TUDURY, E. A.; NAVARRO, I. T.; BATISTA, T. N. Sorologia e histopatologia de Toxoplasma gondii e Neospora caninum em cães portadores de distúrbios neurológicos. Semina: Ciências Agrárias, Londrina, v. 23, n. 1. p. 9-14, 2002.

GROËR, M. W.; YOLKEN, R. H.; XIAO, J. C.; BECKSTEAD, J. W.; FUCHS, D.; MOHAPATRA, S.; SEYFANG, A.; POSTOLACHE, T. T. Prenatal depression and anxiety in Toxoplasma gondii-positive women. Amercian Gynecological Society, New York, v. 204, n. 5, p. e1-7, 2011.

HARVEY, A. M.; GREEFFYDD-JONES, T. J. Feline Inflamatory liver disease. In: ETTINGER, S. J.; FELDMAN, E. C. (Ed.). Textbook of veterinary internal medicine-diseases of the dog and the cat.7. ed. St. Louis, Minissouri: Elservier Sounders, 2010. p. 1643-1648.

HOFFMAN, A. R.; CADIEU, J.; KIUPEL, M.; LIM, A.; BOLIN, S. R.; MANSELLI, J. Cutaneous toxoplasmosis in two dogs. Journal of Veterinary Diagnostic Investigation, Columbia, v. 24, n. 3, p. 636-640, 2012.

HUTCHISON, W. M.; DUNACHIE, J. F.; SIIM, J. C.; WORK, K. Coccidian-like nature of Toxoplasma gondii. British Medical Journal, London, v. 1, n. 5689, p. 142144, 1970.

HUTCHISON, W. M.; DUNACHIE, J. F.; WORK, K.; SIIM, J. C. The life cycle of the coccidian parasite, Toxoplasma gondii in the domestic cat. Transactions of the Royal Society of Tropical Medicine and Hygiene, London, v. 65, n. 3, p. 380-399, 1971.

LANGONI, H.; MATTEUCI, G.; MEDICI, B.; CAMOSSI, L. G.; RICHINI-PEREIRA, V. B.; DA SILVA, R. C. Detection and molecular analysis of Toxoplasma gondii and Neospora caninum from dogs with neurological disorders. Revista da Sociedade Brasileira de Medicina Tropical, Uberaba, v. 4, n. 3, p. 365-368, 2012.

LAPPIN, M. R. Segredo em medicina interna de felinos. Porto Alegre: Artmed, 2004.

Protozoal and miscellaneous infections. In: ETTINGER, S. J.; FELDMAN, E. C. Textbook of veterinary internal medicine. 6. ed. St Louis: Elsevier Saunders. 2005. cap. 168, p. 638-646.

Feline Toxoplasmosis raises health concerns for humans. DVM Newsmagazine, Boulevard, v. 14, n. 3, p. 40-43, june 2002. Disponível em: <http:// veterinarynews.dvm360.com/dvm/data/articlestandard// dvm/392002/32688/article.pdf $>$. Acesso em: 20 ago. 2012.

LINDSAY, D. S.; DUBEY, J. P.; BUTLER, J. M.; BLAGBURN, B. L. Mechanical transmission of Toxoplasma gondii oocysts by dogs. Veterinary Parasitology, Amsterdam, v. 73, n. 1-2, p. 27-33, 1997.

LOPES, M. G.; MENDONÇA, I. L.; FORTES, K. P.; AMAKU, M.; PENA, H. F. J.; GENNARI, S. M. Presence of antibodies against Toxoplasma gondii, Neospora caninum and Leishmania infantum in dogs from Piauí. Revista Brasileira de Parasitologia Veterinária, Jaboticabal, v. 20, n. 2, p. 111-114, 2011.

LOPES-MORI, F. M. R.; MISUKA-BREGANÓ, R.; BITTENCOURT, L. H. F. B.; DIAS, R. C. F.; GONÇALVES, D. D.; CAPOBIANGO, J. D.; REICHE, E. M. V.; MORIMOTO, H. K.; FREIRE, R. L.; NAVARRO, I. T. Gestational toxoplasmosis in Paraná State: Brazil: prevalence of IgG antibodies and associated risk factors. The Brazilian Journal of Infectious Diseases, Salvador, v. 17, n. 4, p. 405-409, 2013.

LUCAS, S. R. R.; HAGIWARA, M. K.; RECHE, A.; GERMANO, P. M. L. Ocurrence of antibodies 
to Toxoplasma in cats naturally infected with immunodeficiency virus. Brazilian Journal of Veterinary Research Animal Science, São Paulo, v. 35, n. 1, p. 4145, 1998.

MARQUES, J. M.; ISBRECHT, F. B.; LUCAS, T. M.; GUERRA, I. M. P.; DALMOLIN, A.; SILVA, R. C.; LANGONI, H.; SILVA, A. V. Detecção de anticorpos anti-Toxoplasma gondii em animais de uma comunidade rural do Mato Grosso do Sul, Brasil. Semina: Ciências Agrárias, Londrina, v. 30, n. 4, p. 889-898, 2009.

McGAVIN, M. D.; ZACHARY, J. F. Pathologic basis of veterinary disease. 5. ed. Elsevier: St. Louis, 2012. 1321 p.

MILLER, N. L.; FRENKEL, J. K.; DUBEY, J. P. Oral infections with Toxoplasma cysts and oocysts infelines, other mammals and birds. Journal of Parasitology, Lawrence, v. 58, n. 5, p. 928-937,1972.

MIRÓ, M.; MONTOYA, A.; JIMÉNEZ, S.; FRISUELOS, C.; MATEO, M.; FUENTES, I. Prevalence of contrabodies to Toxoplasma gondii and intestinal parasites in stray, farm and household cats in Spain. Veterinary Parasitology, Amsterdam, v. 126, n. 3, p. 249-255, 2004.

MONTEIRO, S. G. Parasitologia na medicina veterinária. São Paulo: Roca, 2010.

NAVARRO, I. T.; BREGANÓ, R. M.; MORI, F. M. R. L.; RODRIGUES, T. O.; SANTOS, T. R.; BRESCIANI, K. D. S. Control program of congenital toxoplasmosis. Toxoplasma gondii: prevalence in humans and animals, genetic structure and role in disease distribution. New York: Nova Publishers, 2013.

NAVARRO, I. T.; FREIRE, R. L.; VIDOTTO, O.; OGAWA, L.; KANO, F. S. Estudo comparativo entre soro e plasma na pesquisa de anticorpos anti-Toxoplasma gondii pela técnica de imunofluorescência indireta em cães atendidos no Hospital Veterinário da Universidade Estadual de Londrina-PR. Semina: Ciências Agrárias, Londrina, v. 18, v. 1, p. 15-21, 1997.

NESBIT, J. W.; LOURENS, D. C.; WILliAMS, M. C. Spastic paresis in two littermate pups caused by Toxoplasma gondii. Journal Soulth Africa Veterinary Association, Pretoria, v. 52, n. 3, p. 243-246, 1981.

NICOLLE, C.; MANCEAUX, L. Sur un protozoaire nouveau du gondi. Archives des Instituts Pasteur de Tunis, Tunísia, v. 54, n. 2, p. 216-218, 1909.

PAPICH, M. G. Manual saunders: terapêutico veterinário. 2. ed. São Paulo: MedVet, 2009. 774 p.

PARK, C. H.; IKADAI, E.; YOSHIDA, H. ISOMURA, H.; INUKAI, H.; OYAMADA, T. Cutaneous toxoplasmosis in a female japanese cat. Veterinary Pathology, Amsterdam, v. 44, n. 5, p. 683-687, 2007.

PLUGGE, N. F.; FERREIRA, F. M.; RICHARTZ, R. R. T. B.; SIQUEIRA, A.; DITTICH, R. L. Ocurrence of antibodies against Neospora caninum and Toxoplasma gondii in dogs with neurological sings. Revista de Parasitologia Veterinária, Jaboticabal, v. 20, n. 3, p. 202206, 2011.

PORTO, L. C.; DUARTE, E. C. Association between the risk of congenital toxoplasmosis and the classification of toxoplasmosis in pregnant women and prenatal treatment in Brazil, 1994-2009. International Society for Infectious Diseases, Hamilton, v. 16, n. 7. p. 480-486, 2012.

POWELL, C. C.; BREWER, M.; LAPPIN, M. R. Detection of Toxoplasma gondii in the milk of experimentally infected lactating cats. Veterinary Parasitolosy, Amsterdam, v. 102, n. 1-2, p. 29-33, 2001.

SÁFADI, M. A. P. Toxoplasmose. Pediatria Moderna, São Paulo, v. 36, n. 1-2, p. 7-23, 2000.

SAKAMOTO, C. A. M.; COSTA, A. J.; GENNARI, S. M.; PENA, H. F.; TONIOLLO, G. H.; LOPES, W. D.; BICHUETTE, M. A.; BETINI, M. A.; AMARANTE, A. F.; BRESCIANI, K. D. S. Experimental infection of pregnant queens with two major Brazilian clonal lineages of Toxoplasma gondii. Parasitology Research, New York, v. 105, n. 5, p. 1311-1316, 2009.

SARMENTO, L. V. C.; TUDURY, E.; ALBUQUERQUE, E. R.; MAGALHÃES, P. K. L. Coleta, análise e interpretaão do líquido céfalo-raquidiano de cães e gatos - revisão. Clínica Veterinária, São Paulo, ano V, n. 25, p. 19-26, 2000.

SCHARES, G.; PANTCHEV, N.; BARUTZKI, D.; HEYDORN, A. O.; BAUER, C; CONRATHS, F. J. Oocysts of Neospora caninum, Hammondia heydorni, Toxoplasma gondii and Hammondia hammondi in faeces collected from dogs in Germany. International Jounal for Parasitology, Oxford, v. 35, n. 14, p. 1525-1537, 2005.

SCHÖLER, N.; KRAUSE, K.; KAYSER, O.; MÜLLER, R. H.; BOMER, K.; HAHN, H.; LIESENFELD, O. Atovaquone nanosuspensions show excellent therapeutic effect in a new murine model reactivated toxoplasmosis. Antimicrobial Agents Chemotherapy, Washington, v. 45, n. 6, p. 1771-1779, 2001.

SILVA, M. C.; FIGHERA, R. A.; BRUM, J. S.; GRAÇA, D. L.; KOMMER, G. D.; IRIFOYEN, L. F.; BARROS, C. S. L. Aspectos clínicos patológicos de 620 casos neurológicos de cinomose em cães. Pesquisa Veterinária Brasileira, Rio de Janeiro, v. 27, n. 5, p. 215-220, 2007. 
SILVA-FILHO, M. F.; TAMEKUNI, K.; TOLEDO, R. S.; DIAS, R. C. R.; LOPIS-MORI, M. R.; MITSUKABREGANÓ, R.; THOMAZ-SCCOL, V.; GARCIA, J. L.; FREIRE, R. L.; VIDOTTO, O.; NAVARRO, I. T. Infection by Toxoplasma gondii and Leishmania spp. in humans and dogs from rural settlements in Northern Paraná State, Brazil. Semina: Ciências Agrárias, Londrina, v. 33, p. 3251-2164, 2012. Suplemento 2.

SMART, M. E.; DOWNEY, R. S.; STOCKDALE, P. H. Toxoplasmosis in cat associated with cholangitis and progressive pancreatitis. The Canadian Veterinary Journal, Ottawa, v. 14, n. 122, p. 313-316, 1973.

SOBRINHO, L. S. V.; ROSSI, C. N.; VIDES, J. P.; BRAGA, E.T.; GOMES, A. A.; DE LIMA, V. M.; GENEROSO, D.; LANGONI, H.; LEUTENEGGER, C.; BIONDO, A. W.; LAURENTI, M. D.; MARCONDES, M. Coinfection of Leishmania chagasi with Toxoplasma gondii, feline immunodeficiency vírus (FIV) and feline leukemia vírus (FeLV) in cats from an endemic area of zoonotic visceral leishmaniasis. Veterinary Parasitology, Amsterdam, v. 187, n. 1-2, p. 302-306, 2012.

SOUZA, H. J. Coletâneas em medicina e cirurgia felina, Coletâneas em medicina e cirurgia felina. Rio de Janeiro: L. F. Livros de Veterinária, 2003.

SUTER, M. M.; HAUSER, B.; PALMER, D. G.; OETTLI, P. Polymyositis - polyradiculitis due to toxoplasmosis in the dog: serology and tissue biopsy as diagnostic aids. Zentalblatt Veterinarmedizin, Hamburg, v. 31, n. 10, p. 792-798, 1984.
SWINGER, R. L.; SHMIDT, K. A.; DUBIELZIG, R. R. Keratoconjunctivitis associated with Toxoplasma gondii in a dog. Veterinary Ophthalmology, California, v. 12, n. 1, p. 56-60, 2009.

TENTER, A. M.; HECKEROTH, A. R.; WEISS, L. M. Toxoplasma gondii: from animals to humans. International Journal for Parasitology; New York, v. 30, p. 1217-1258, 2000.

URQUHART, G. M.; ARMOUR, J.; DUNCAN, J. L.; DUNN, A. M.; JENNINGS, F. W. Parasitologia veterinária. 2. ed. Rio de Janeiro: Guanabara Koogan, $1998.273 \mathrm{p}$.

WEBB, J. A.; KELLER, S. L.; SOURTEHORN, E. P.; ALLEN, D. G.; PEREGRINE, A. S.; DUBEY, J. P. Cutaneous manifestations of disseminated Toxoplasmosis in an Immunosuppressed dog. Journal of the American Animal Hospital Association, Schaumburg, v. 41, n. 4, p. 198-202, 2005.

WITTE, H. M.; PIEKARSKI, G. Die OocystenAusscheidung bei experimentell infizierten Katzen in Abhängigkeit vom Toxoplasma-Stamm. Zeitschrift furParasitenkunde, Berlin, v. 33, n. 4, p. 358-360, 1970.

WORK, K. Resistance of toxoplasma gondii encysted in pork. Acta Pathologica Microbiologica Scandinavic et Imunnologica, Denmark, v. 75, n. 1, p. 85-923, 1968.

ZHANG, S.; WEI, M. X.; DING, Z. Y.; XU, X. P. Comparison a modified agglutination test (MAT), IHAT and ELISA for detecting antibodies to Toxoplasma gondii. Acta Parasitologica Medica Entomologica Sinica, China, v. 8, n. 4, p. 199-203, 2001. 
